\title{
Impact of gaming algorithms on the behavior of an individual and regional migration flows
}

\author{
Elena L. Iakovleva \\ Department of Philosophy \\ Kazan Innovative University named after V.G. Timiryasov \\ Kazan, Russia
}

\author{
Natalya S. Seliverstova \\ Institute of Management, Economics and Finance \\ Kazan Federal University \\ Kazan, Russia \\ nat-grig17@yandex.ru
}

\author{
Olga V. Grigoryeva \\ Department of Psychology \\ Kazan Innovative University named after V.G. Timiryasov \\ Kazan, Russia
}

\begin{abstract}
The paper examines game algorithms of behavior in the context of new form of identity - electronic nomadism, through which the modern individual becomes mobile and fluid, thereby enhancing the migration flows. It is shown that migration flows influence the economic development of the regions. From the point of view of regional economic development, migration can be viewed as the mobility of human capital. The effect of gaming algorithms on the behavior of an individual was identified, which, among other factors, may be due to the choice of the place of residence and economic activity, creating risks and opportunities for sustainable regional development.
\end{abstract}

Keywords - regional development, game, metaprinciple of life, electronic nomadism, migration, human capital

\section{INTRODUCTION}

An e-nomad is an independent entity in the digital space of the Internet. The new algorithms and patterns in their behavior represent, on the one hand, the challenges, and on the other hand, - the development opportunities, including those of the modern regional economic systems. Due to the electronic nomadism, today an institutional person is a more mobile resource, both in terms of social adaptation (to changes, new technologies and products) and in terms of geography (currently, labor migration is a common phenomenon). The above speaks in favor of the mobility of human capital. Let us pay attention to the following fact: for a rater long time, economists have been speaking about the role of labor migration in the development of economic relations. According to V.I. Lenin, it is the migration of population movement that is the progressive force which "...destroyed the patriarchal isolation... of stationary pre-capitalist relations... and pushes the industrial development forward" [1]. The modern authors exploring the issues of labor migration also confirm its significant impact on the economic development of various states [2]. It should be emphasized that the mutual influence of the above factors is essential, since the development of the territory directly affects the direction and magnitude of migration flows [3].

In "the new economic theory of migration", its authors O. Stark and J. Taylor [4] define migration of employees to other labour markets as an effective opportunity for households to overcome the shortage of capital with minimal risk. M. Todaro [5] notes that the decision to migrate is largely determined by the individual ideas of the migrants about the development of certain territories. Therefore, the management of migration flows is significantly influenced by such factors as the transparency of information, the territory brand and the sociopsychological factors determined by the identity of an individual in the society. The latter is associated not only with the immensity of the virtual environment, but also with the gaming instinct of a person, superimposed on it.

The modern space of the social is fully immersed in the gaming atmosphere: all segments and sectors of society use the gaming algorithm. We are speaking of the political, business, military, administrative, mathematical, logical, linguistic, psychological, economic, educational, and other games. The game spirit permeates the modern television programs. Computer games and their total character in human life, beginning from the early childhood ${ }^{1}$, leads to ambiguous consequences, causing anxiety on the part of teachers, doctors, psychologists, and parents. Today, a game leaves the position strictly allotted to it, absorbing the culture, blurring the boundaries between itself and real life. The existence of a game is multifaceted, and any action can be described in gaming terminology (e.g., "the roles are set wrongly", "let us play the situation over", "a new team took power", etc.). It is no coincidence that among the many personality characteristics there is a Homo Ludens/gaming man, referring

\footnotetext{
${ }^{1}$ In Western Europe, the modern younger generation is called "head down generation" because of their morbid dependence on mobile electronic systems.
} 
to the famous treatise of a Dutch researcher Johan Huizinga [6].

In the modern space, a game is so topical that it turns into a key metaprinciple of life, making it possible to speak about the game with the world and the game of world. The spatialtemporal totality of a game makes people (often against their will and consciousness) engage into it. However, today games undergo transformations. The new form of a human identity electronic nomadism - has a lot to do with the changes of game modus.

Among the gaming algorithms, actively used by digital nomads in a virtual space, and later in life, we highlight the following: promptness, attentiveness, ability to react quickly to changes in the situation, flexibility associated with adjusting to changes, creative abilities manifested in combining of the heterogeneous. These qualities contribute to efficient operation of a particular sphere, including economic one.

The objective of this work is to analyze the impact of gaming algorithms on the behavior of an individual and on the regional migration flows.

\section{METHODS}

The informational basis of the study consists of monographs and articles on the issues of e-nomadism, games as cultural phenomenon, labor migration, human capital, and regional development.

When conducting the research, we used the analytical, abstract-logical and dialectical methods of cognition.

\section{RESULTS}

A game was originally set to a human, assisting to adapt to the world, not to be afraid to start over, to be optimistic. We agree with F. Schiller, who believed that a game is not a fleeting pastime or entertainment, but a synonym of the transformed life of a human. In Schiller's "Letters about the aesthetic education of man", there is a link of a game with the culture, embodying the harmony of the sensual and the rational, content and form, desire and duty, pleasure and suffering, reality and ideal [7].

In C. Spencer we find a "hygienic" interpretation of a game as a competitive activity which allows the joy of victory, the triumph over the enemy to be manifested, which is tantamount to the success in the struggle for existence. This is due to the fact that a human possesses an excess of unused energy, which generates a game. According to C. Spencer, a game can be considered a kind of an exercise, useful to humans [8]. Completely opposite views were held by M.Latsarus, who believed that a human starts a game when tired, in order to restore their strength; that is, according to the German psychologist and philosopher, a game acts as a recreation and as a way of mental relaxation. K. Gross argued that the roots of a game are found in naturally-hereditary impulses (instincts) that require training and implementation. Among the game characteristics, K. Gross lists freedom, playing condition, integrity, orderliness and clarity of behavior of the participants [8]. In the process of a game, the dual behavior is manifested, inherent in the human psyche: at one and the same time, a player believes and does not believe in what is happening. A Dutch animal psychologist F.Y. Buitendijk characterized a game as an activity that forms fantasy, imagination, and intelligence [8]. A Swiss psychologist and philosopher J. Piaget argued that a game is a form of creativity with a certain purpose. It acts as a selforganizing and dynamic body, helping a person to adapt to reality and to restore the equilibrium relationships with the environment. Among the criteria of a game, J. Piaget lists fun, freedom, completeness, mastery, assimilation, and strong interest in the result, which help to adapt oneself and win Self over the world [9]. J. Huizinga in his book Homo ludens proclaims a game to be a universal of culture [6].

A game appears to be in tune with electronic space and electronic nomad. Possessing huge potential, the electronic space creates games and game situations for the nomads, teaching, training and introducing them into a workflow; this creates a feeling of lightness, excitement, accessibility, courage, and adventure. The gaming algorithm is adopted not only by the acquisition of information, education, and acquaintance with different cultures/innovations in the on-line system, but also by the living activity per se. Today, the system of different purchases via the Internet (food/clothes/things/equipment etc.) becomes the norm. The virtual world opens up broad prospects for the nomads, offering them a world without borders. In this world, you can literally live, almost without leaving it. Virtuality becomes a workspace and a place of leisure, allowing a nomad move smoothly from one space to another at any time to, and often combining them. The uncertainty of the subsequent development of the situation and the ability to choose from multiple alternatives; a chance to win even after losing; the opportunity to start from the beginning, changing the failed strategy of development - all this makes the gaming algorithms in electronic space quite common and attractive. The gaming algorithms in the virtual space do not constrain the identity of a nomad, representing a field of freedom for them. A nomad is often not limited by anything in their choice, taking a voluntary decision on the entry to /exit from a project. The game allows taking a break within the monotonous work in the virtual space, switching one's attention to something else, and relaxing. Worlds of virtuality that pop-up unexpectedly and distract a nomad, create the situation of unpredictability. The gaming process captures a personality, promoting engagement and efficiency. The virtual space and gaming algorithm of search help to find a job, like-minded people, or people with similar situations that promotes cooperation and problem-solving.

In the Internet, the search of information/partner, the possibility to choose between them, the modeling of various situations are constructed as a game. The search of information, its tracking, often in invisible mode, elaborating projects on its basis, creation of the product and its promotion on the market resemble a competitive game of hunting down the enemy.

One of the game functions, distinguished by us, is training. Due to various virtual models and Internet simulators, a person 
can not only learn and master a particular field of activity, but also train, testing their skills.

A gaming algorithm is manifested at the level of various online/conference relations, built as a "question - answer" gamedialogue. This significantly expands the communication field along various dimensions, and also helps to involve a large number of communicants. Consulting on various problems and issues also acquire a gaming form.

The increased possibilities of electronic communication affect the regional migration flows and indirectly - the development of certain territories due to the mobility of a human capital. Such impact of electronic communication on the regional migration flows is manifested through:

- the increased accessibility of social infrastructure through electronic environment (established relationships with governmental and educational institutions, healthcare institutions, and employers, publishing information about vacancies; with representatives of real estate agencies);

- the reduced transaction costs of a human capital mobility (documents are submitted and forwarded in electronic format);

- the changes in people's consciousness, who are not afraid to turn to the Internet for information; the manifestation of gaming algorithms, greater flexibility and willingness to change in their behavior.

These factors affect people who turn from e-nomads into the real ones, becoming migrants. The skills related to the accumulated gaming algorithms of the virtual space become useful to them in their future activities.

The notion of migration per se is a complex phenomenon, having not a trivial structure. From the point of view of the regional economic development, migration can be viewed as the human capital mobility. The gaming algorithm involves variability, which makes first the electronic nomads and then the nomad-migrant rather flexible and able to adapt to the quickly changing situations, including in the economic sphere. The ability to change may offer many scenarios and help avoid crisis areas, thus contributing to disclosing the talents and self-improving of a nomad-migrant.

The Conception of state migration policy of the Russian Federation for the period up to 2025 contains the notions of temporary migration, long-term migration, seasonal labor migration, and labor migration. The analysis of these concepts leads to the conclusion that the Conception defines external labor migration as temporary international labor migration with a view of employment and performing of works (services). The term "internal migration" is mentioned in the definition of temporary migration, but its essence is not disclosed [10].

A.Yu. Lukyanova distinguishes between the concepts of "labor migration" and "commercial migration". She interprets commercial migration as "spontaneous (not organized by the government) territorial movements of entrepreneurs, carried out with different periodicity, for purchasing and selling the consumer goods within and out of the country, that allow obtaining profit from wholesale and retail trade and commercial activities". Lukyanova interprets the term "labor migration" as "territorial movements of the population with different frequency within and out of the country, which involve implementation of labor market skills and abilities of migrants" [11].

The increased quality of human capital has a significant economic impact with a substantial time lag. Therefore, F. Droller [12] argues that in 1914 in Argentina, in the regions with historically higher shares of European population, GDP per capita increased 80 years later than the European immigrants arrived to Argentina en masse. His calculations show that this long-term effect was associated with a higher level of human capital, which the immigrants brought to Argentina.

The study by A. Rodríguez-Pose and V. Berlepsch [13] shows that the countries which had a more diverse population more than 130 years ago, are much richer today. In particular, the authors traced the short, medium and long-term economic impact of the population diversity as a result of great immigration waves of the late 19th and early 20th centuries in the United States. Therefore, the long-term sustainable development of territories is directly related to the increase in human capital of the population, which lives and carries out economic activities on this territory.

In this regard, to attract people with high human capital for future sustainable economic development, the regions should pay special attention to the creation of public spaces, especially in large cities. This creates conditions for labor migration and increases the attractiveness of the improved territory in the eyes of the current and potential residents.

The analysis of labor mobility in the Russian Federation by types of economic activity in 2015, performed by L.A. Tretyakova, showed that the highest labor mobility was observed in the regions with the positive dynamics of profitable business activities [14].

It is important to understand that the higher rank of innovative potential the area has, the more migrant workers arrive to these regions. This said, the innovative potential is the cumulative ability of the regional economy to implement the investment projects aimed at meeting the needs of the population, thus providing the innovative development of production and consumption [14]. The gaming algorithms help e-nomads and nomads-migrants to be active and mobile, to track information, to analyze the market situation based on the available data, to learn from the experience and to introduce it in their business, to respond quickly to the changes in the economic situation, to find the best alternatives, to restructure the development strategies, to make decisions, including those associated with forecasting. The above helps the e-nomad and the nomad-migrant to change their actions, enhancing their flexibility, facilitated by the gaming algorithms of behavior. In the modern world, due to the gaming algorithms in a virtual space, the electronic nomad, and later the nomad-migrant 
acquires a lot of opportunities to study, work, relax, forming and manifesting themselves. The gaming algorithms, in the form of freedom, improvisation, fancy, and flexibility, help an individual to find their own style and express themselves in the social, implementing the targeted energy, initiative and resourcefulness.

\section{DISCUSSION}

Many researchers and also the mass media note that most often the basis of mass migration of people are economic reasons as well as military conflicts, natural disasters, technogenic catastrophes, etc.

We note that, in addition to the traditionally distinguished reasons for the movement of human capital between different areas (relocation of low-skilled workers to economically developed countries; resettlement between the countries with the same level of development due to social or cultural factors; movement of labour from the former Soviet Union and Eastern European countries to Western Europe and the United States; skilled workers moving from wealthy countries to developing countries for higher earnings or career), essential are the features of modern identity of an individual, which arise from the proliferation of electronic nomadism and gaming algorithms as a metaprinciple of life. Today, the electronic nomadism and gaming instinct increasingly affect the migration flows, bringing not only material wealth, but also enjoyment of life to people.

\section{CONCLUSION}

In the modern world, human capital becomes mobile and moveable due to the new identity - the electronic nomadism and gaming instinct, which is confirmed by active migration flows. The management of migration flows is significantly influenced by such factors as the transparency of information, the brand territory and the socio-psychological factors, determined by the electronic form of an individual's identity in the society. As R. Kundakchyan and N. Grigoryeva noted [15], various aspects of individualbehavior have a significant impact on the economic development of a territory and the practice of the contractual relationships implementation. The development of digital technologies directly affects the behavior of individuals [16], giving rise to constant changes in the social environment. On this basis, the gaming algorithm manifested by nomads-migrants relieves many tense aspects, allowing to readjust depending on the situation and to change the direction of economic development of a region.

It is shown that, from the point of view of regional economic development, migration can be viewed as the human capital mobility. We agree that increasing the quality of human capital has a significant economic impact with a substantial time lag. In this regard, we emphasize that the long-term sustainable development of territories is directly related to the increase in human capital of the population, which lives and carries out economic activities on this territory.

The presented analysis of virtual environment and gaming algorithms' impact on the individual behavior and regional migration flows expands the knowledge of the causes of human capital movement in the modern world.

\section{REFERENCES}

[1] Lenin V.I. The Development of Capitalism in Russia. The Process of the Formation of a Home Market for LargeScale Industry / Moscow: State publishing house of political literature. 1971. Vol.3, Is.2. - 548 p.

[2] Nivorozhkina L.I., Kosova N.A. Evolution of scientific views on labor migration as a driving force for the development of world economic relations / Bulletin of Rostov State Economics University (RINKh). 2014. Vol. 1(45). pp. 148-155.

[3] Magomedova L. A. Influence of the regional socio-economic development on labor migration / Bulletin of Makhachkala branch of MADI. 2014. Vol. 14. pp. 197-199.

[4] Taylor J.E. Migration: new dimensions and characteristics, causes, consequences and implications for rural poverty. URL: http://www.fao.org/docrep/003/X980 8e/x9808e07.htm.

[5] Harris J., Todaro M. Migration, Unemployment, and Development: A Two-Sector Analysis. The American Economic Review. 1970. Vol. 60. pp.126-142.

[6] Huizinga J. Homo ludens. A study of the play-element in culture. 1949.

[7] Schiller F. Letters Upon The Aesthetic Education of Man. 1794.

[8] Apinyan T.A. Game in the space of the serious. Game, myth, ritual, dream, art, and others / Saint Ptersburg: Saint Ptersburg University publishers. 2003. $400 \mathrm{p}$.

[9] Piaget J. The development of thought: Equilibration of cognitive structures. (Transl. A. Rosin). Oxford, England: Viking. 1977.

[10] Conception of state migration policy of the Russian Federation for the period up to 2025. Moscow. 2012.

[11] Lukyanova Yu.A. External labor migration in Stavropol region / Modern problems of migration in Russia: works of all-Russian scientific conference. 2003. 167 p.

[12] Droller F. Migration, Population Composition and Long Run Economic Development: Evidence from Settlements in the / The Economic Journal. 2017. DOI: 10.1111/ecoj.12505.

[13] Rodríguez-Pose, Andrés and von Berlepsch, Viola, Does Population Diversity Matter for Economic Development in the Very Long-Term? / Historic Migration, Diversity and County Wealth in the US. 2017. URL: https://ssrn.com/abstract=3049903.

[14] Tretyakova L.A. Influence of innovative development of the regions on labour migration. Innovative development of the Russian economy $/ 9^{\text {th }}$ International scientific-practical conference. Ministry of Education and Science of the Russian Federation, Russian University of Economics named after G.V. Plekhanov; Russian Research Fund for Humanities. 2016. pp. 410-412.

[15] Kundakchyan R., Grigoryeva N. The influence of the opportunistic behavior on the contractual relationship / Journal of Economics and Economic Education Research. 2016. Vol. 17. pp. 68-73.

[16] Seliverstova N., Iakovleva E., Grigoryeva O. Human behavior in digital economy: the main trends / Advances in Economics, Business and Management Research. 2017. Vol. 38. pp. 600-605. 